\title{
Child Abuse and Compliance on Child Protection Policy in Private and Public Basic Educational Institutions
}

\author{
Jeremay M. Cervancia ${ }^{1}$, Kristine U. Hernandez ${ }^{1}$, Maria Rosario Rodavia ${ }^{2}$, Erwin Roxas ${ }^{3}$ \\ De La Salle University - Graduate School-ELMD ${ }^{1}$, Arellano University ${ }^{2}$ \\ Manila Central University ${ }^{3}$ \\ Manila, Philippines
}

\begin{abstract}
In this study, the researchers presented reports on child abuse and bullying in all regions of the Philippines to give a picture of incidence of cases after the establishment of the Child Protection Policy by the Department of Education (DepEd). Then, the researchers investigated on how child protection issues underlying the essence of the DepEd Child Protection Policy are generally understood and implemented within the school's context. Adopting an instrument from UNICEF, the researchers through a descriptive survey, examined the level of awareness of teachers in two private and two public basic educational institutions in an urban city in Metro, Manila, Philippines regarding child protection issues that they encounter in the classroom setting; and verified how the DepEd Child Protection Policy is actually being implemented in one of these schools. Information about observed cases on abuse and bullying, although mostly shared conservatively, significantly revealed the existence of child protection issues. Moreover, the researchers deem the important contribution that teachers play in such undertaking especially in the prevention and early detection of child abuse and bullying. Consequently, this study recommends for further research on the implementation of the DepEd Child Protection Policy mainly focusing on the monitoring of the system adopted by schools and on probing on the capacity building activities afforded to teachers in both public and private educational settings. This study contributes to the Philippines policy making on creation, updating, implementation, and monitoring of Child Protection Laws and Policies.
\end{abstract}

\section{Introduction}

Violence against children (VAC) is a crucial global problem that every country in the world faces and tries to end. This violence come in varied forms and generally include neglect; physical, sexual, and psychological abuse; maltreatment and exploitation; and cruelty and discrimination. Both boys and girls are vulnerable to violence, especially younger children. VAC can happen anywhere at home, in school, communities, and online. Violence affects all children regardless of ethnicity or socio-economic status. According to United Nations (UN) World Report on VAC (2006), about one (1) billion children have experienced several sexual violence, emotional violence, bullying, or have witnessed violence in the past years, and almost three quarters are in Asia. According to UNICEF, more than half of Filipino children experience violence during their childhood, with boys twice as likely to become victims of abuse. Children who are victims of abuse tend to develop low self-esteem, feel sad and fearful, avoid interaction with other people, and experience anxiety attacks. Notably, violence can have a devastating and life-long impact on children's physical and psychological wellbeing. To address this global conflict, the Convention on the Rights of the Child (CRC) was created. Adopted by the UN General Assembly on November 20, 1989, the CRC is the first universal legally binding code of children's rights in history. It establishes global standards to ensure the protection, survival, development, and participation of all children, without discrimination. Countries that ratify the treaty pledge to protect children from all forms of violence and to advance the rights of children primarily to education, health and special care, security, privacy, and a decent standard of living. States that have ratified the UN CRC are legally bound by it and have made a commitment to taking the necessary legal, budgetary, administrative, and other measures to implement it. According to the Council for the Welfare of Children \& UNICEF (2016) the country participated in the National Baseline Study on Violence against Children (NBSVAC) which is a nationwide research aimed to gather national epidemiological data on violence against children experienced sought to: 1) make an estimate of the prevalence of violence against children (VAC) in various forms and settings; 2 ) enumerate the social and health consequences of VAC; 3 ) assess children's awareness and utilization of healthy, legal, and welfare services related to VAC; and 4) obtain stakeholder's views about VAC including the perceived reasons why VAC persist in the communities, adequacy/inadequacy of existing services, type of resources and services still needed, readiness to implement VAC services as well as their capacity-building needs. The study was conducted in 
172 randomly selected barangays in the 17 regions of the country. In each barangay, 25 households were systematically sampled and, in each household, 1 eligible child was selected as the final respondent. Three thousand eight hundred sixty-six (3866) children and youth aged 13-24 years participated in the study giving an overall response rate of $89.85 \%$. Majority of the children belonged to the middle economic class; $55.6 \%$ came from the rural areas and $44.4 \%$ came from the urban areas. About $99.3 \%$ of the respondents attended school; majority of them were in high school and college during the survey. An estimate of $25 \%$ of Tagalog speaking mostly comprised the respondents followed by the Cebuanos, Ilokanos, and Ilonggos. About $12.3 \%$ of them were indigenous people. From this perspective, the Philippine Plan of Action to End Violence against Children (PPAeVAC) was developed by the Council for the Welfare of Children which translates the findings of the NBS-VAC into action. The PPAeVAc is a multi-sectoral roadmap designed towards a progressive reduction of violence against children in the country. This is the commitment of the government to build an enabling environment that respects, protects, and fulfils the rights of all children in the country. It is focused on breaking the cycle of violence by addressing the causes at the demand side, building the capacity of children to protect themselves, improving the legislative environment, enhancing integrated services for preventing and responding to violence, ensuring access to social services, monitoring of interventions, and evaluating the implementation of the plan. This is the expression of the Philippine government's commitment and contribution to the attainment of the ASEAN Regional Plan of Action on the Elimination of Violence against Children in 2015-2025 (Global Partnership to End Violence Against Children, 2016). The Philippine Laws on Child Protection are Republic Act (R.A.) 7610 Anti-Child Abuse Act, R.A. 10627 Anti-Bullying Act, R.A. 9344 Juvenile Justice and Welfare Act, R.A. 9208 Anti-Trafficking in Persons Act, R.A. 9775 Anti-Child Pornography Act of 2009, R.A. 10630 Establishing a Comprehensive Juvenile Justice Welfare System, R.A. 10634 Expanded AntiTrafficking in Persons Act, and R.A. 9262 AntiViolence Against Women and their Children Act.

This study inquired on the appropriateness and effectiveness of the existing child protection laws in the Philippines specifically on the implementation of the DepEd Order (D.O.) Order No. 40, s. 2012 referred to as DepEd Child Protection Policy.

\section{Methodology}

This study made use of a descriptive research design to present a picture of child abuse and bullying in the Philippines after establishment of the DepEd Child Protection Policy. A quantitative approach was employed to find out the view and awareness of the teachers about DepEd Child Protection Policy. The researchers conducted a survey in two private and two public basic educational institutions in an urban city in Metro Manila, Philippines. The questionnaire (see in Appendix) utilized in the survey included items categorized as describing neglect, exploitation, bullying and discrimination, physical abuse and corporal punishment, emotional and psychological abuse, and sexual abuse that were used by UNICEF in its quantitative studies (2014) to measure violence against children. Results from the survey were tabulated according to those categories. A qualitative approach was also done through a review of the Child Protection Policy of one of the participating schools. Analysis from this review provided a context for the results of the survey and direction for future works in the effective implementation of the policy.

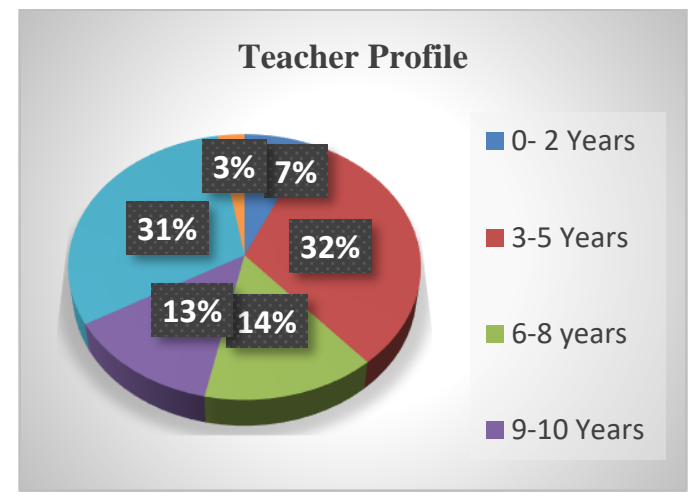

Figure 1. Profile of Participants

Participants who responded in the survey consisted of all grade 7 to 10 level teachers who are currently teaching in the 2 private and 2 public basic educational institutions who accommodated the researchers to conduct the study. A total of 86 teachers responded to the survey, $32 \%$ has been teaching for three to five years and $31 \%$ for eleven years (see Figure 1).

Ethical considerations were ensured by this study. Informed consent was requested from the school administrators in order to conduct the survey and gain access to the school's child protection policy. Participants anonymity were maintained throughout the study and information gained from the survey and policy review were treated with utmost confidentiality.

\section{Results and Discussion}

The Department of Education (DepEd) recognizes that for a teaching-learning environment to be truly beneficial and meaningful for learners, it should promote children's right to education while preserving their right to protection from all forms of violence. 
In 2012, DepEd issued a landmark child protection policy aimed at providing special protection to children who are seriously threatened or endangered by their vulnerabilities to circumstances that may impact on their development and learning. The DepEd order No. 40, s. 2012, also known as the "Policy and Guidelines on Protecting Children in School from Abuse, Violence, Exploitation, Discrimination, Bullying and Other Forms of Abuse," shall ensure that all schools become enabling environment that are conducive to education. As such, the best interest of the children for security and participation, should be given paramount consideration in all decisions and actions involving them. Accordingly, the policy reiterates a zero-tolerance policy on all forms of violence and opens avenues to prevent, protect, and support the healing of children caught in situations of neglect, abuse, exploitation, bullying, and discrimination in the school setting.

Through this policy, the Department of Education ordered all elementary and secondary public and private schools, among others, to: 1) ensure the institution of effective child protection policies and procedures, and monitor compliance thereof; 2) ensure that the school adopts a child protection policy; 3 ) ensure that all pupils and students, school personnel, parents or guardians, and visitors and guests are made aware of child protection policy; 4) organize and create a Child Protection Committee (CPC) who is to provide timely information on key actions and resources to adequately manage the incidence of serious and complex cases involving children that are brought to their attention by different sectors within the school community; 5) conduct capacity building activities for the CPC on child protection measures and protocols; 6) conduct disciplinary proceedings and maintain a record of such proceedings; and 7) coordinate with other agencies and authorities for appropriate assistance in the performance of their function to address cases of abuse, violence, exploitation, discrimination, bullying, and other similar acts.

\subsection{Private and Public Basic Educational Institutions Child Protection Policy}

In both private and public schools, the DepEd Child Protection Policy is very much in placed. The policy aims to protect pupils and students from all forms of violence that may be inflicted by adults, persons in authority as well as their fellow students, including bullying.

Figure 2 illustrates the view and awareness on the DepEd Child Protection Policy of all the teachers involved in the study. Out of 86 total respondents, results revealed responses leaning toward items that indicate the teachers' view on the importance of detecting and reporting of child abuse and their awareness of the presence of Child Protection
Committee and programs or other information being disseminated in their school regarding child abuse.

\section{View on Child Abuse \& Awareness of Child Protection Policy}

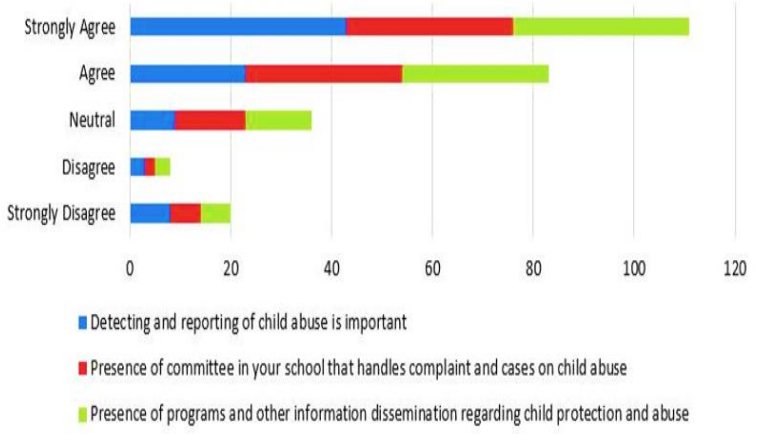

Figure 2. View and Awareness on Child Protection Policy

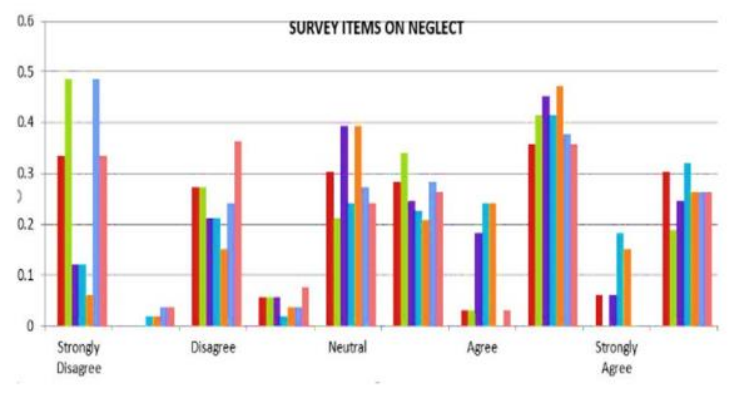

Figure 3. Results on Observed Cases of Neglect

Neglect is to the "failure to provide for the development of the child in all spheres: health, education, emotional development, nutrition, shelter, and safe living conditions, in the context of resources reasonably available to the family or caretakers and causes or has a high probability of causing harm to the child's health, or physical, mental, spiritual, moral, or social development" (WHO, 1999 in UNICEF, 2014, p. 20). The information on the aspects of neglect that were observed by the teachers in their students. In this study, physical neglect was operationalized in terms of the lack of provision for basic needs that are essential in learning like food, clothing and school supplies. For psychological neglect, the indicators apparent in the students included the lack of supervision, interest, and support by parents.

Physical abuse of a child is "that which results in actual or potential physical harm from an interaction or lack of an interaction, which is reasonably within the control of the parent or a person in a position of responsibility, power, or trust" (WHO, 1999 in UNICEF, 2014, p.20). 


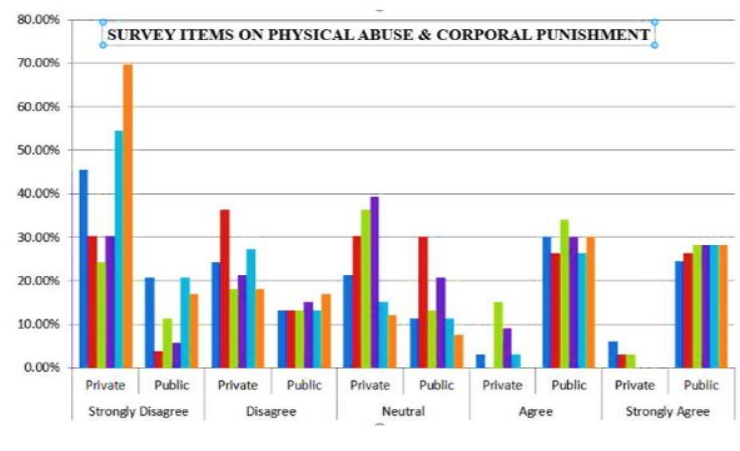

Figure 4. Results on Observed Cases of Physical Abuse including Corporal Punishment

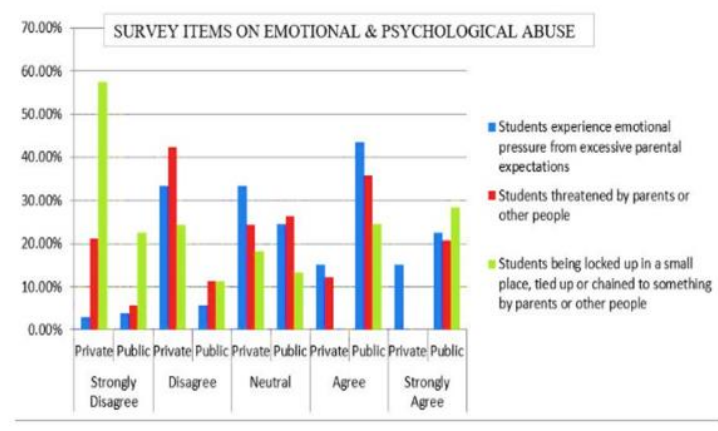

Figure 5. Results on Observed Cases of Emotional and Psychological Abuse

Emotional abuse is defined as "the failure to provide a developmentally appropriate, supportive environment including the availability of a primary attachment figure, so that the child can develop a stable and full range of emotional and social competencies commensurate with her or his potentials and in the context of the society that the child dwells" (WHO, 1999 in UNICEF, 2014, p.20).

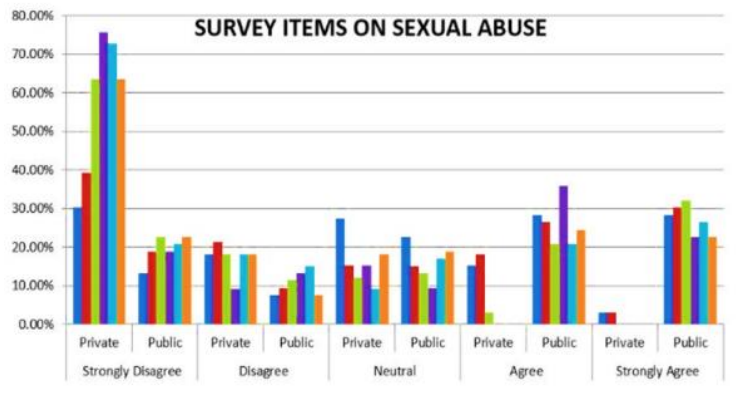

Figure 6. Results on Observed Cases of Sexual Abuse

Sexual abuse is "the involvement of a child in a sexual activity that he or she does not fully comprehend, is unable to give informed consent to, or for which the child is not developmentally prepared and cannot give consent or that violate the laws or social taboos of society... it is evidenced by "an activity between a child and an adult or another child who by age or development is in a relationship of responsibility, trust or power, the activity being intended to gratify or satisfy the needs of the other person" (WHO, 1999 in UNICEF, 2014, p. 20).

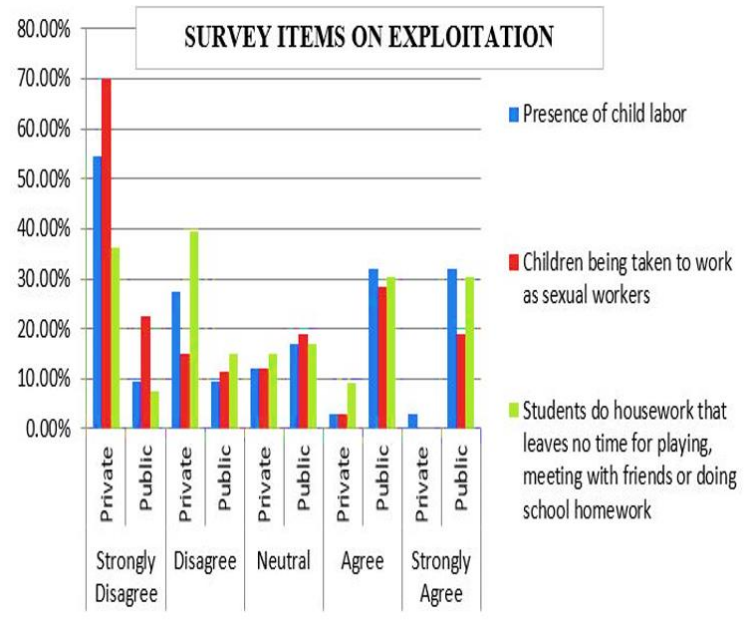

Figure 7. Results on Observed Cases of Exploitation

Exploitation as it is usually linked to commercial purposes refers to "the use of the child in work or other activities for the benefit of others ... including child labour and child prostitution" (WHO, 1999 in UNICEF, 2014, p. 20). Notable among these cases is the burden of economic responsibility that is forced in children which hinders seriously their development.

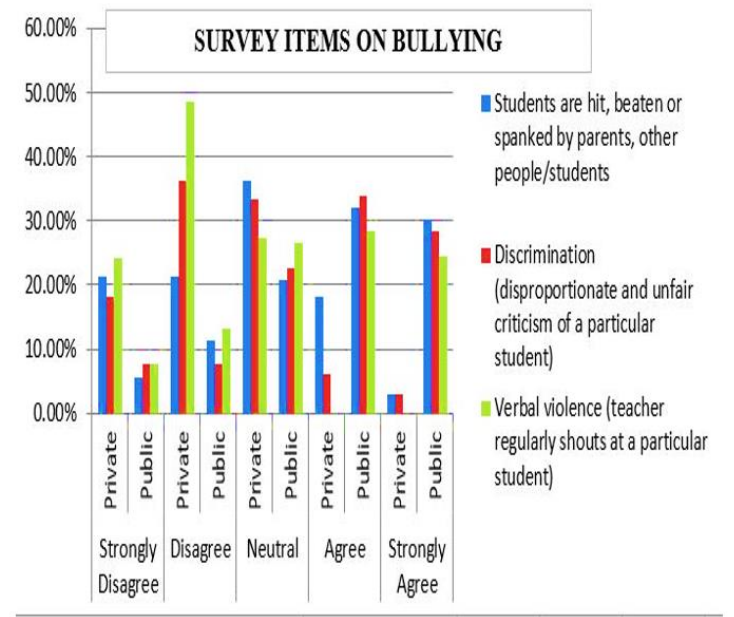

Figure 8. Results on Observed Cases of Bullying and Discrimination

Bullying or peer abuse according to the DepEd Child Protection Policy (2012) applies to 'the wilful aggressive behaviour that is directed towards a particular victim who may be out-numbered, younger, weaker, with disability, less confident, or otherwise vulnerable which results in physical and mental abuse, harassment, intimidation, or humiliation." In this 
study, bullying is connected to discrimination (i.e. act of exclusion, distinction, restriction or preference arising from differences in age, ethnicity, sex, sexual orientation and gender identity, language, religion, politics, nationality, etc.).

Overall, the study found out that the participants are aware of the DepEd Child Protection Policy and of the existence of cases that are being addressed by this policy. Although most information gained about observed cases on child abuse and bullying, were generally shared conservatively, findings that revealed the occurrence of child protection issues are considered relevant especially in providing guidance to the implementation of the policy.

\subsection{Child Protection Policy Review in Private and Public Basic Educational Institutions}

The school under study adopted and institutionalized the implementation of the child protection policy with the primary purpose of ensuring a nurturing education for their students that is free from all forms of harassment and violence. This end is also envisioned by the State pursuant to the 1987 Constitution and in adherence to the Convention on the Rights of the Child as it (State) intends to promote the rights of children to assistance and special protection from all forms of violence that are detrimental to their development.

The school identified and specifically defined the entities who are to comply with the policy which necessarily involve the pupils and students, school personnel, including its guests and service providers. As provided in Article 218 of the Family Code of the Philippines, the school recognizes the important roles that administrators, teachers, academic and nonacademic personnel will play as they exercise special parental authority and responsibility over pupils and students under their supervision, instruction, and custody.

For the procedures in handling complaints and cases, the school practices diligence to ensure that due process is complied with. A detailed statement of procedures that clearly enumerate the process of investigation, starting with the conduct of filing of the complaint up to the rendering of the decision, is provided in the policy. Furthermore, the school also indicated in the policy a precise system for handling of cases that considered the following components: immediate responses, reporting, fact-finding and documentation, intervention, and referral.

With regards to disciplinary proceedings and measures to manage the cases, while the DepEd Child Protection Policy only made mention to impose nonpunitive measures in accordance with positive and non-violent discipline, the school, on the other hand allotted a section in its policy to describe the disciplinary measures to be applied with concrete examples of activities suggested ranging from written reprimand, community service to suspension, exclusion or expulsion proportionate to the act committed. Additionally, the school also requires that the offenders undergo an intervention program that enjoins parent participation which will be administered or supervised by the school's Child Protection Committee.

The school created its Child Protection Committee which is composed of the following members: 1) Principal of the High School and Grade School department; 2) Head of the Guidance and Placement Office; 3) Discipline Officer of the High School and Grade School Department; 4) Representative of the Parents Teachers Association; and 5) Representative of the Supreme High School and Grade School Student Council. Operating privately, it does not involve any representative from the community like what is suggested in the DepEd Protection Policy.

The school described the specific functions and responsibilities of the Child Protection Committee, the mandate of which is to ensure strict and proper implementation of the policy through affordance of support and coordination with appropriate agencies and authorities. Such functions and responsibilities however did not cover the proposal of the DepEd Child Protection Policy to draft a Code of Conduct, initiate a system to identify probable cases, and to implement a school-based referral and monitoring system for identified cases.

Moreover, the task on undertaking information dissemination programs were not delegated to the Child Protection Committee but instead assigned it to the Principal along with other tasks that relate to monitoring of compliance, organizing capacitybuilding activities, recording and reporting of all case proceedings.

Furthermore, even if the school made mention of the capacity building of the Child Protection Committee along with its guidance counselors and teachers, as an important assignment of the principal, its policy did not elaborate on how to go about it like that which is stipulated in the DepEd Child Protection Policy (Article III Section 11).

This study also verified on the implementation of the DepEd Child Protection Policy in Public Schools through an interview conducted with the teachers and Junior and Senior High Schools students in one school in a city in Visayas, Philippines. Detailed results of the interview are disclosed in the following discussions:

The commendable finding are: (1) There is a presence of Child Protection Committee; (2) presence of Child Protection Center; (3) there is a strong coordination between the school and Local Government Unit in promoting Child Protection; (4) Active participation of the Supreme Student Government in conducting symposium on antibullying (5) Efficient process in addressing bullying; (6) Enforcement of positive discipline; (6) Wide 
information campaign on promoting the "best interest of the child"; and (7) Incidents were properly documented

The non-conformities are: (1) The school is not that proactive compared to the Local Government Unit when it comes to the campaign against child abuse, exploitation and discrimination; and (2) DepEd Orders on Child Protection are not posted on the bulletin board

Overall, the comparison of the school's child protection policy against the directives explicitly specified in the Department Order No. 40 s. 2012 revealed general compliance. Perhaps, future appropriations on the aspects of the policy pointed out by the review as lacking, will help make improvements in the implementation of the DepEd Child Protection Policy so that eventually all cases of child abuse and bullying will be eradicated.

\section{Conclusions and Recommendations}

Based on the findings of the study, the following conclusions are drawn:

1. Awareness on the DepEd Child Protection Policy is crucial for all teachers as they play special parental authority and responsibility in the supervision, instruction, and custody over their pupils and students.

2. Reporting of cases is valuable in the effective implementation of the DepEd Child Protection Policy as it opens an avenue for the prevention and early detection of child abuse and bullying.

3. Discipline begins at home with parents who are the first and primary educators of the children. Such formation should carry significant responsibility and respect for the rights of children.

Hence, partnership by the school with parents to support child protection initiatives must be very much a part of the school's program.

From the conclusions realized in this study, the following recommendations are proposed:

1. For the schools to allot provisions in their Child Protection Policy for monitoring of compliance along with development of a system for identification of probable cases of abuse and bullying; and creation of a Code of Conduct or Prefects of Discipline that will guide them in the effective reporting and handling of cases.

2. For the schools to thoroughly invest efforts on information dissemination and capacity building not only for its Child Protection Committee but foremost for teachers to aid them in preventing, protecting and supporting their pupils and students afflicted by situations related to abuse and bullying.

3. For further research on the implementation of the DepEd Child Protection Policy mainly focusing on the monitoring of the system adopted by schools to ensure compliance; and on probing on the capacity building activities afforded to teachers in both public and private educational settings to overcome challenges that they encounter when faced with cases on abuse and bullying that are detrimental to children's development and learning.

\section{References}

[1] Aquino, C. Executive Order No. 209, s. 1987, "The Family Code of the Philippines". Retrieved online through http://www.officialgazette.gov.ph/1987/07/06/executiveorder-no-209-s-1987/

[2] Child Protection Monitoring and Evaluation Reference Group. Measuring Violence against Children: Inventory and assessment of quantitative studies. Division Data, Research and Policy, UNICEF. New York, 2014. Retrieved online through: https://data.unicef.org/wp-content/ uploads/2014/11/Measuring-Violence-against-ChildrenInventory-and-assessment-of-quantitative-studies.pdf

[3] Council for the Welfare of Children \& UNICEF. National Baseline Study on Violence Against Children: Philippines Executive Summary. October 2016. Retrieved online through; https://www.unicef.org/philippines/ PHL_NBSVAC_Results_ES.pdf

[4] Global Partnership to End Violence Against Children. The Philippines: An Historic Opportunity to End Violence Against Children. Discussion Paper. May 2016 Retrieved online through; http://www.aidsdatahub.org/sites/ default/files/publication/Philippines_Pathfinder_to_end_vi olence_against_children_2016.pdf

[5] Republic of the Philippines. DepEd Order No. 40. s. 2012, "DepEd Child Protection Policy". Retrieved online through; http://www.deped.gov.ph/sites/default/files/ order/2012/DO_s2012_40.pdf

[6] Republic of the Philippines. The Constitution of the Republic of the Philippines.1987. Retrieved online through http://www.officialgazette.gov.ph/constitutions/

[7] UNICEF East Asia \& Pacific, ASEAN. Ending violence against children in ASEAN member States: Baseline study of priority areas under the ASEAN Regional Plan of Action on the Elimination of Violence against Children A snapshot as of 2016. By Afrooz Kaviani Johnson, 2017. Retrieved online through https://www.unicef.org/eap/reports/endingviolence-against-children-asean-member-states

[8] UN General Assembly. Convention on the Rights of the Child. 20 November 1989, United Nations, Treaty Series, vol. 1577, p. 3. Retrieved online through http://www.refworld.org/docid/3ae6b38f0.html 
International Journal for Cross-Disciplinary Subjects in Education (IJCDSE), Volume 10, Issue 1, March 2019

United Nations, Secretary-General's Study on Violence Against Children. World Report Against Violence on Children. By Paulo Sergio Pinheiro, 2006. Retrieved online through https://www.unicef.org/violencestudy/

I.\%20World\%20Report\%20on\%20Violence\%20against\% 20Children.pdf 